\title{
Using stiffness to assess injury risk: Comparison of methods for quantifying stiffness and their reliability in triathletes
}

\author{
Anna V Lorimer ${ }^{\text {Corresp., }}$ 1, 2 , Justin W L Keogh ${ }^{1,2,3}$, Patria A Hume ${ }^{2}$ \\ 1 Faculty of Health Sciences and Medicine, Bond University, Gold Coast, Queensland, Australia \\ 2 Sports Performance Research Institute New Zealand, Auckland University of Technology, Auckland, New Zealand \\ 3 Faculty of Science, Health, Education and Engineering, University of the Sunshine Coast, Sunshine Coast, Queensland, Australia \\ Corresponding Author: Anna V Lorimer \\ Email address: alorimer@bond.edu.au
}

Background. A review of the literature has indicated that lower body stiffness, defined as the extent to which the lower extremity joints resists deformation upon contact with the ground, may be a useful measure for assessing Achilles injury risk in triathletes. The nature of overuse injuries suggests that a variety of different movement patterns could conceivably contribute to the final injury outcome, any number and combination of which might be observed in a single individual. Measurements which incorporate both kinetics and kinematics (such as stiffness) of a movement may be better able to shed light on individuals at risk of injury, with further analysis then providing the exact mechanism of injury for the individual. Stiffness can be measured as vertical, leg or joint stiffness to model how the individual interacts with the environment upon landing. However, several issues with stiffness assessments limit the effectiveness of these measures to monitor athletes' performance and/or injury risk. This may reflect the variety of common biomechanical stiffness calculations (dynamic, time, true leg and joint) that have been used to examine these three stiffness levels (vertical, leg and joint) across a variety of human movements (i.e. running or hopping) as well as potential issues with the reliability of these measures, especially joint stiffness. Therefore, the aims of this study were to provide a comparison of the various methods for measuring stiffness during two forms of human bouncing locomotion (running and hopping) along with the measurement reliability to determine the best methods to assess links with injury risk in triathletes.

Methods. Vertical, leg and joint stiffness were estimated in 12 healthy male competitive triathletes on two occasions, 7 days apart, using both running at $5.0 \mathrm{~ms}^{-1}$ and hopping $(2.2 \mathrm{~Hz})$ tasks.

Results. Inter-day reliability was good for vertical (ICC=0.85) and leg $(I C C=0.98)$ stiffness using the time method. Joint stiffness reliability was poor when assessed individually. Reliability was improved when taken as the sum of the hip, knee and ankle $(I C C=0.86)$. The knee and ankle combination provided the best correlation with leg stiffness during running (Pearson's Correlation $=0.82$ ).

Discussion. The dynamic and time methods of calculating leg stiffness had better reliability than the "true" method. The time and dynamic methods had the best correlation with the different combinations of joint stiffness, which suggests that they should be considered for biomechanical screening of triathletes. The knee and ankle combination had the best correlation with leg stiffness and is therefore proposed to provide the most information regarding lower limb mechanics during gait in triathletes. 


\section{Using stiffness to assess injury risk: Comparison of methods for quantifying}

2 stiffness and their reliability in triathletes

3 Anna V Lorimer ${ }^{1,2}$, Justin W L Keogh ${ }^{1,2,3}$ and Patria A Hume ${ }^{2}$

$4 \quad{ }^{1}$ Faculty of Health Sciences and Medicine, Bond University, Gold Coast, Australia

$5 \quad{ }^{2}$ Sports Performance Research Institute New Zealand (SPRINZ), AUT-Millennium, Auckland

6 University of Technology, Auckland, New Zealand

$7 \quad{ }^{3}$ Faculty of Science, Health, Education and Engineering, University of the Sunshine Coast,

8 Sunshine Coast, Queensland, Australia

9

10 Correspondence: Dr Anna V Lorimer, Faculty of Health Sciences and Medicine, Bond University,

11 Gold Coast, Australia.E-mail: alorimer@bond.edu.au

12 Word count (excluding references): 5,089

13

14

15 
16 Using stiffness to assess injury risk: Comparison of methods for quantifying

17 stiffness and their reliability in triathletes

Background. A review of the literature has indicated that lower body stiffness, defined as the extent to which the lower extremity joints resists deformation upon contact with the ground, may be a useful measure for assessing Achilles injury risk in triathletes. The nature of overuse injuries suggests that a variety of different movement patterns could conceivably contribute to the final injury outcome, any number and combination of which might be observed in a single individual. Measurements which incorporate both kinetics and kinematics (such as stiffness) of a movement may be better able to shed light on individuals at risk of injury, with further analysis then providing the exact mechanism of injury for the individual. Stiffness can be measured as vertical, leg or joint stiffness to model how the individual interacts with the environment upon landing. However, several issues with stiffness assessments limit the effectiveness of these measures to monitor athletes' performance and/or injury risk. This may reflect the variety of common biomechanical stiffness calculations (dynamic, time, true leg and joint) that have been used to examine these three stiffness levels (vertical, leg and joint) across a variety of human movements (i.e. running or hopping) as well as potential issues with the reliability of these measures, especially joint stiffness. Therefore, the aims of this study were to provide a comparison of the various methods for measuring stiffness during two forms of human bouncing locomotion (running and hopping) along with the measurement reliability to determine the best methods to assess links with injury risk in triathletes. 
41 Results. Inter-day reliability was good for vertical $(\mathrm{ICC}=0.85)$ and leg $(\mathrm{ICC}=0.98)$ stiffness using 42 the time method. Joint stiffness reliability was poor when assessed individually. Reliability was 43 improved when taken as the sum of the hip, knee and ankle (ICC $=0.86)$. The knee and ankle 44 combination provided the best correlation with leg stiffness during running (Pearson's Correlation $45 \quad=0.82)$.

Discussion. The dynamic and time methods of calculating leg stiffness had better reliability than the "true" method. The time and dynamic methods had the best correlation with the different combinations of joint stiffness, which suggests that they should be considered for biomechanical screening of triathletes. The knee and ankle combination had the best correlation with leg stiffness and is therefore proposed to provide the most information regarding lower limb mechanics during gait in triathletes. 


\section{Introduction}

56 Overuse injuries, are characterised by progressive onset of symptoms with no specific causal event.

57 The causative mechanisms of overuse injuries have been suggested to be related externally to

58 training loads and equipment or internally due to the biomechanics of the individual (Kannus

59 1997). The progressive nature of overuse injuries suggests an accumulation over time, of tissue

60 damage, that alone goes unnoticed and heals given sufficient time (Lorimer \& Hume 2014). Once

61 damage reaches a tipping point however, pain and dysfunction result (Lorimer \& Hume 2014).

62 Achilles tendon injuries in triathletes conceivably follow this pattern of tendon tissue micro

63 damage, accumulated over time resulting in a progressively weakened tendon which is more likely

64 to maintain further damage (Lorimer \& Hume 2014). Research into overuse injuries tends to isolate

65 individual components of a movement to track risk factors. An accumulation of sub-threshold

66 tissue challenges has been proposed as the mechanism of injury, suggesting that individual

67 movement components that may predispose an athlete to injury may be too small to detect. It has

68 been shown in a number of human movements, that similar final outcomes can be achieved through

69 a variety of coordination strategies (Hiley et al. 2013; Whiteside et al. 2015). Likewise, it is posited

70 that progressive injuries have a variety of different contributors, any combination of which can

71 lead to the final pain and dysfunction outcome.

73 It is believed that the study of movement patterns combining both kinetics and kinematics into

74 single risk factor measures may provide greater insight into risk of injury than isolated movement

75 components. Stiffness, of the lower limb 'springs' provides a means of assessing the influence of

76 kinetics and kinematics on the tissues of the lower limb during running. Review of the literature

77 indicated that five risk factors were associated with risk of Achilles injuries in running athletes

78 (Lorimer \& Hume 2014; Lorimer \& Hume 2016). All five of these risk factors; surface stiffness, 
79 arch height, peak braking force, peak propulsive force and peak vertical force, linked to changes

80 in lower limb stiffness (Lorimer \& Hume 2014; Lorimer \& Hume 2016).

81

82 Running as a bouncing gait has been modelled using the spring-mass model, a point mass balanced 83 on a massless, compressible, linear spring (Blickhan 1989; Günther \& Blickhan 2002; McMahon

84 \& Cheng 1990; Seyfarth et al. 2002; Seyfarth et al. 2003). The stiffness measure provides an 85 holistic view of how the body accommodates the impacts of running, with the contributions of 86 joints, muscles, tendons, ligaments and bones and the range of motion all contributing to the 87 stiffness output (Butler et al. 2003). Stiffness therefore provides a useful tool to investigate how 88 the combination of various movement components may combine to create an injurious 89 environment (Lorimer \& Hume 2016).

91 The basic model of lower extremity stiffness has been represented in a number of mathematical 92 forms (figure 1). Vertical stiffness is the most generalised, modelling the body as a point mass 93 perched on top of a compressible, massless spring with compression of the spring represented by 94 a negative vertical displacement of the centre of mass (McMahon \& Cheng 1990). Vertical 95 stiffness can be measured using force platforms and can be estimated from flight time and contact 96 time making this measurement appropriate for assessment of gait in a natural environment (Morin 97 et al. 2005). **insert Figure 1 here**

100 The vertical displacement of the centre of mass used in calculations for vertical stiffness occurs 101 due to changes in hip, knee and ankle angles, resulting in the leg becoming effectively shorter. 
102 Modelling leg stiffness where the leg is a spring, and there is compression of the 'leg spring' in

103 response to contact with the ground, estimates stiffness taking into account the angle of leg swing

104 (from ground contact to mid-stance), accounting for horizontal movement (Blickhan 1989;

105 McMahon \& Cheng 1990). During hopping, horizontal velocity is virtually zero, therefore leg

106 stiffness is in essence equal to vertical stiffness (Farley et al. 1991). As anterior posterior braking

107 force was determined to have a clear impact on Achilles injury risk, some incorporation of

108 horizontal forces into the model should be considered (Coleman et al. 2012; Lorimer \& Hume 109 2014).

110

111 The compression of the 'leg spring' is achieved by rotation around the hip, knee and ankle joints,

112 to dissipate landing forces and store energy for elastic return in the next step or hop.. The individual

113 joints have been modelled as rotational springs which have associated stiffness due to muscular

114 activity controlling the speed and magnitude of the joint rotations, and mechanical behaviour of

115 tendons, ligaments and other structures comprising the joints (Butler et al. 2003). Joint stiffness

116 therefore provides insight into the body's control strategies to attenuate the impact forces on

117 landing and to the relative loading at each individual joint. When it comes to understanding overuse

118 injuries, it is unclear which joint injurious mechanics can be attributed to or whether it is the

119 interaction between the joints or extent to which joints compensate for each other which is

120 important in understanding risk. In the support moment concept proposed by Winter (1980) it is

121 noted that both the hip and knee have highly variable moments within and between individuals

122 even when a similar support moment and gait velocity are maintained. It is possible, that looking

123 at various combinations of the joints may provide insight into athletes relative risk of overuse

124 injuries around particular lower body joints such as the Achilles tendon. 
126 Triathletes and other endurance running athletes typically sustain near constant running velocities

127 over a large portion of their training and races. The ability to maintain running velocity may require

128 relatively consistent (reliable) vertical and leg stiffness. However, as vertical and leg stiffness may

129 be controlled by the coordinated action at the ankle, knee and hip during the first half of stance to

130 absorb impact and store energy for return during toe off, subtle differences in the body positions

131 at foot strike may require step to step adjustments at the level of the ankle, knee and hip joints,

132 thereby altering the individual joints stiffness. Similar to other biomechanical outputs that

133 demonstrate that the variability of measurements may become greater as the measurement

134 becomes more specific or isolated (Bartlett et al. 2007; Stergiou \& Decker 2011), it is therefore

135 likely that joint stiffness may be less stable (reliable) than leg or vertical stiffness. Such

136 observations are supported by the reliability work investigating stiffness in single leg hopping

137 (Diggin et al. 2016; Joseph et al. 2013) and overground running (Joseph et al. 2013). When

138 comparing different hopping frequencies, the joints with the largest range of motion and therefore

139 greatest potential for variability, the hip and knee had weak reliability (Diggin et al. 2016). When

140 hopping is performed at the reported natural frequency of $2.2 \mathrm{~Hz}$, reliability of the knee stiffness

141 is improved, however hip reliability still remains poor (Diggin et al. 2016). The reliability of leg

142 stiffness during hopping is generally reported to be good in populations of mixed athletes (Diggin

143 et al. 2016; Joseph et al. 2013; Pruyn et al. 2016).

145 Another issue affecting the potential applicability of using a variety of stiffness measures to

146 monitor performance and injury risk concerns the challenges in assessing running in ecologically

147 valid situations. Currently, lower extremity stiffness (vertical, leg and joint) have been measured 
148 for over ground running and treadmill running as well as hopping, with the method of measurement

149 largely dictated by space and equipment (Farley et al. 1991; Farley \& Gonzalez 1996; Morin et al.

150 2005). In order to measure ground reaction force for over ground running, targeting of a force

151 platform is required, which has been suggested to alter aspects of the gait cycle and the forces

152 associated with the individual foot strike (Challis 2001). Various methods have been adopted to

153 minimise the targeting effect, but the number of steps is also limited and it is difficult to control

154 the running speed with overground running (Kluitenberg et al. 2012). Treadmill running allows

155 the runner to adopt a more steady state biomechanics with the control of speed (Riley et al. 2008).

156 The development of force plates built into treadmills allows the measurement of the ground

157 reaction force for multiple consecutive steps in a confined space. Comparison of kinetics and

158 kinematics for overground and treadmill running suggest treadmill running is comparable but not

159 directly equivalent to overground running (Riley et al. 2008). Due to space constraints and the

160 inability to record a sufficient number of foot strikes, hopping has also been used as a surrogate

161 for running, as they both are bouncing gaits and requiring less space and technology to measure

162 than overground or treadmill running. Hopping is usually conducted at a rate of $2.2 \mathrm{~Hz}$ (Farley et

163 al. 1991) suggested as the natural hopping frequency. While a relationship between hopping

164 stiffness and running performance has been well established (Butler et al. 2003; Chelly \& Denis

165 2001), a direct relationship between hopping and running stiffness has not, to the authors'

166 knowledge, been investigated in a triathlete population. As triathletes are not typically a group of

167 athletes with much experience in hopping, it is unclear if the relationship reported in the literature

168 between hopping and running stiffness for athletes who regularly run, and jump would also be

169 observed in triathletes. This is an important consideration if hopping was to be used as a surrogate

170 for running for injury risk factor analysis in triathletes. 
172 To investigate whether stiffness can be used routinely to monitor running performance and injury

173 risk, the reliability of the various measures of stiffness needed to be assessed. Where increased

174 variability is present due to the inherent nature of human movement, understanding the variability

175 that can be expected and to what extent the variability is minimised elsewhere in the kinetic chain

176 is fundamental to understanding the results. It is also important to quantify the comparability of

177 the various methods of measuring stiffness to determine the most appropriate measures to use for

178 an investigation and to provide insight into the mechanism for any stiffness changes that may be

179 observed.

180

181 The complexity of the human neuromusculoskeletal system allows for a relatively infinite 182 combination of joint moment and activation patterns to be utilised when performing repeated 183 activities, such as running and jumping. Joint compensation is supported by the observation of 184 stable ground reaction forces and joint kinematics within subjects but highly variable hip and knee 185 joint moments during both walking and running (Winter 1980; Winter 1984). For example, a

186 decrease in ankle stiffness may be adjusted for by an increase in knee stiffness resulting in an

187 overall more stable knee+ankle stiffness. It is important therefore to understand the reliability of 188 combinations of joint stiffness as well as the reliability of the individual joints stiffness in isolation.

190 The aim of the study was to provide a comparison of the various methods for measuring stiffness

191 during two forms of human bouncing locomotion (running and hopping) along with the

192 measurement reliability to determine the best methods to assess links with injury risk in endurance

193 athletes such as triathletes. Vertical and leg stiffness were hypothesised to show better reliability 
194 than the individual joints, even though the hip, knee and ankle all appear to play a role in the

195 control of leg stiffness during running and hopping. Combining the joints in different combinations

196 is hypothesised to reduce the measurement variability to allow interday assessment. Hopping is

197 proposed to not be a good surrogate for running in triathletes when assessing injury risk.

\section{Methods}

199 Twelve well-trained, male triathletes $(34 \pm 5 \mathrm{y}, 75.6 \pm 6.2 \mathrm{~kg}, 1.80 \pm 0.04 \mathrm{~m})$ volunteered for the

200 study. All triathletes were currently competitive as top level age group athletes in either Olympic

201 or long distance events. Personal best times in the previous season of under $2 \mathrm{~h} 20$ min for Olympic

202 distance or under $10 \mathrm{~h}$ for Iron distance and the ability to run for over $2 \mathrm{~min}$ at $4.0 \mathrm{~min} / \mathrm{km}$ was

203 required. Triathletes were excluded if they currently had a lower limb injury or had not been back

204 to full training for at least six weeks following a previous lower limb injury. To avoid the possible

205 effects of maturation (Oliver \& Smith 2010) and ageing (Silder et al. 2008; Strocchi et al. 1991),

206 triathletes under 16 and over 50 were excluded. Triathletes were not excluded based on foot strike

207 type to assess the utility of stiffness measures in a natural triathlon population. All triathletes

208 provided fully informed written consent prior to participation. Ethical approval was obtained for

209 all testing procedures from the University ethics committee (AUTEC reference \#11/94).

210 A test-retest between-day protocol on two separate days, seven days apart was performed.

211 Triathletes were requested to keep training the same in the week prior to each testing session

212 (monitored using TrainingPeaks ${ }^{\mathrm{TM}}$, endurance load monitoring and coaching software) to

213 minimise changes in running biomechanics which might occur because of fatigue due to different

214 training volumes and intensities. Triathletes were not asked to refrain from exercise at any point

215 to minimise disruption. 
216 A treadmill graded run was performed initially on an instrumented treadmill, followed by bent

217 knee and straight knee hopping tasks. Thermal effects on stiffness measures as a result of repeated

218 energy dissipation are unknown, therefore tasks were not randomized. As the hopping task

219 required practice, this was scheduled after the run trial. Running pace was not randomized to

220 reduce the injury risk that may be associated with accelerating to the faster paces from an initial

221 slow pace. Due to the racing level of the triathletes and the distances and speeds experienced in

222 training, this protocol was unlikely to fatigue the triathlete and therefore non-randomisation was

223 deemed acceptable (Abt et al. 2011). Following warm-up and familiarization of 5 min at 6.0

$224 \mathrm{~min} / \mathrm{km}(2.8 \mathrm{~m} / \mathrm{s})$, triathletes ran continuously for $2 \mathrm{~min}$ at each of 5.5, 5.0, 4.5 and $4.0 \mathrm{~min} / \mathrm{km}$

$225(3.0,3.3,3.7$ and $4.2 \mathrm{~m} / \mathrm{s})$. Cool down consisted of $1 \mathrm{~min}$ each at $5.5 \mathrm{~min} / \mathrm{km}$ and $6.0 \mathrm{~min} / \mathrm{km}$.

226 Acceleration and deceleration between running velocity blocks were set to $0.1 \mathrm{~m} / \mathrm{s}^{2}$. In training,

227 triathletes use pace to monitor running speed rather than horizontal velocity. Therefore, running

228 pace was used to provide a familiar measure and to ensure that future injury outcome data can be

229 accommodated to the triathletes training environment. Data were collected for the final $20 \mathrm{~s}$ of

230 each 2 min block to ensure gait had stabilised following pace change. Triathletes were unaware of

231 when recording was taking place.

232

233 After a 5 min rest, triathletes were given as much time as needed to familiarise themselves with

234 hopping in time with the metronome. Triathletes performed single leg hopping, first on the right

235 leg and then on the left, on the stationary treadmill (in-ground design with the treadmill belt in line

236 with the laboratory floor). Hopping was carried out first with no instructions other than to keep in

237 time to the metronome set at $2.2 \mathrm{~Hz}$. Hopping was repeated with triathletes instructed to keep the 
238 knee as straight as possible. Ten hops were recorded once rhythm had stabilized to match the

239 metronome frequency, based on visual inspection.

240

241 During the running and hopping tasks, all triathletes wore spandex shorts or trisuits and their own

242 regular training shoes. Height $(\mathrm{mm})$, mass $(\mathrm{kg})$ and bilateral trochanterian height $(\mathrm{mm})$ were

243 recorded according to International Society for the Advancement of Kinanthropometry (ISAK)

244 protocols (Stewart et al. 2011). Retroflective markers (10 mm) were attached to the lower body

245 according to a modified three dimensional (3D) model (see figure 2) based on the models reported

246 by Besier et al. (2003), Tulchin et al. (2010) and Feber et al. (2003). Clusters of four markers, on

247 thermo-moulded plastic shells were attached to the posterior pelvis (over the sacrum), anterior

248 thigh (distal and lateral to avoid the bulk of muscle) and anterior shank (along the tibia).

249 Anatomical markers were attached bilaterally to iliocristale, anterior superior iliac spine,

250 trochanterion, medial and lateral femoral condyle, medial and lateral malleoli, proximal and distal

251 calcaneus centre, the most anterolateral aspect on the distal border of the calcaneus, $1^{\text {st }}$ and $5^{\text {th }}$

252 metatarsal heads and centre line of the forefoot between the $2^{\text {nd }}$ and $3^{\text {rd }}$ metatarsal heads. Following

253 a static standing calibration, femoral condyle and malleoli markers were removed. For dynamic

254 calibration of the hip joint, participants moved first the right then the left leg through a combination

255 of flexion, abduction, adduction and extension (Besier et al. 2003; Piazza et al. 2001). Knee joint

256 centre dynamic calibration involved three squat movements (Besier et al. 2003).

259 A 9-camera VICON motion analysis system (Oxford Metrics Ltd., Oxford, UK) combined with a 
260 Bertec instrumented treadmill (BERTEC Corp, Worthington, OH, USA) were used for kinematic

$261(200 \mathrm{~Hz})$ and vertical, horizontal and lateral ground reaction force $(1000 \mathrm{~Hz})$ collection,

262 respectively. Full analysis of the Bertec instrumented treadmill force performance, both static and

263 dynamic, has been reported by Belli et al. (2001). Vertical force maximal non-linearity was $\pm 0.3 \%$

264 with a relative error of $0.11 \%$. Force differences between the treadmill and an artificial walking

265 leg ranged from \pm 4.6 to \pm 20.9 N. Functional joint positions were determined using a custom built,

266 MATLAB constrained optimization program (Optimization Toolbox, Mathworks Inc.; Natick,

267 MA) detailed by Besier et al. (2003). Joint angles, moments and foot centre of pressure locations

268 were calculated via inverse kinematics using Visual3D software (Visual 3D, C-motion, Inc.;

269 Germantown, MD). Anatomical co-ordinate systems were defined according to specifications

270 reported by Besier et al. (2003). For the single segment foot, the $\mathrm{x}$-axis was the line joining the

271 two calcaneal markers. The y-axis followed the longitudinal axis of the foot from the proximal

272 calcaneal marker, to the forefoot midline marker. The z-axis was orthogonal to the $\mathrm{x}$ and $\mathrm{y}$ axes.

273

274 Variables were averaged over ten steps per leg for each individual for the running trials to allow

275 for step variability (Dalleau et al. 1998)taken from the first full step recorded in the last $20 \mathrm{~s}$ of

276 each running block based on the lack of no significant difference in stride to stride differences

277 for biomechanical measures .(Dalleau et al. 2004; Morin et al. 2005) . Five consecutive hops

278 within $5 \%$ of the $2.2 \mathrm{~Hz}$ hopping frequency were averaged (Granata et al. 2002). Horizontal

279 velocity was taken as treadmill velocity and was assumed to be constant. Stiffness values were

280 normalized to body mass before statistical analysis.

282 Stiffness values were calculated using a custom written Labview program (Labview, National 
283 Instruments Corp.; Austin, TX). Stiffness was calculated for the first half of stance from initial 284 heel contact to maximal vertical ground reaction force for all stiffness measures (Joseph et al. 285 2013). Stiffness calculations were carried out using all the equations stated in Table 1. The method 286 reported by Coleman et al. (2012) was used to calculate $\mathrm{k}_{\text {leg/brake }}$ as absolute change of force and 287 leg length between ground contact and $F_{\max }$. The greater trochanter marker (GTR) was used as 288 reported by Coleman et al. (2012) to give $\mathrm{k}_{\mathrm{leg} / \mathrm{GTR}}$. Improved repeatability is reported from using 289 functional hip and knee joints for defining the leg segments (Besier et al. 2003), therefore the 290 functional hip joint centre (HJC) as the hip marker $\left(\mathrm{k}_{\operatorname{leg} / \mathrm{HJC}}\right)$ was compared to $\mathrm{k}_{\operatorname{leg} / \mathrm{GTR}}$. Joint 291 stiffness combinations, $\mathrm{k}_{\text {sumjoints }}, \mathrm{k}_{\mathrm{hip}+\mathrm{knee}}$ and $\mathrm{k}_{\mathrm{knee}+\text { ankle }}$ were calculated using equations 1-3.

292

* Insert Table 1 here *

294

295

296

297

298

299

300

301 302 303

\section{Equations 1-3}

$$
k_{\text {sumjoints }}=k_{\text {hip }}+k_{\text {knee }}+k_{\text {ankle }}
$$

$$
k_{\text {hip }}+\text { knee }=k_{\text {hip }}+k_{\text {knee }}
$$

$$
k_{\text {knee }}+\text { ankle }=k_{\text {knee }}+k_{\text {ankle }}
$$

Descriptive statistics including group means and standard deviations were calculated for all measures for both hopping and running. Data were assessed for between trial measurement reliability and measurement variability at the $90 \%$ confidence level following log transformation to allow results to be expressed as percentages (Hopkins 2000). Robustness was maintained by using two criteria each to determine the level of reliability and variability (Bradshaw et al. 2010). 
305 Average reliability was determined to be 'good' when the percent difference between means

$306(\mathrm{MDiff} \%)$ was $<5 \%$ and the effect size (ES) was trivial $(0-0.2)$ or small $(0.2-0.6)$ (Hopkins et

307 al. 2009). If one of these criteria were not met, then measurement reliability was interpreted as

308 'average'. 'Poor' reliability meant neither criteria was met (Bradshaw et al. 2010).

310 Measurement variability was assessed from typical error, reported as coefficient of variation

311 percentage (CV\%) (Bradshaw et al. 2010; Hopkins 2000) and intra-class correlation coefficient

312 (ICC) with upper and lower confidence limits (Bradshaw et al. 2010). Criteria for 'small'

313 measurement variability were CV $<10 \%$ (Bradshaw et al. 2010) and ICC $>0.70$ (Bradshaw et al.

314 2010; Hopkins et al. 2009). If CV was $>10 \%$ or ICC $<0.70$ then variability in the measurement

315 was deemed 'moderate'. 'Large' measurement variability was reported if neither criteria for 316 'small' was met.

317

318 For overall reliability, all four variables (effect size, percent difference between means, coefficient

319 of variation and interclass correlation) were assessed. 'Good' reliability required all four criteria

320 to be met. 'Moderate' reliability resulted from one criteria outside the limits, while if two or more

321 criteria were outside the limits, a 'poor' overall reliability was recorded (Joseph et al. 2013).

322

323 Biomechanical stiffness models were checked for comparability using Pearson's correlation

324 coefficient both within the stiffness type and between stiffness types (vertical with leg stiffness

325 and leg with joint stiffness). Leg stiffness and joint stiffness have different units, therefore results 
326 were converted to unitless values prior to comparison using equation 4 (Liew et al. 2017;

327 McMahon \& Cheng 1990) and equation 5 (Rummel et al. 2008).

328

329 Equations 4-5

330

331

$$
D k_{\text {leg }}=\frac{k_{\text {leg }} l_{0}}{m g}
$$

332

$$
D k_{\text {joint }}=\frac{k_{\text {joint }}}{\left(m g l_{0}\right)}
$$

334 A Pearson's correlation coefficient $>0.90$ was interpreted to show 'very large' correlation between

335 the stiffness models or stiffness types. Correlations between 0.70 and 0.90 indicated 'large'

336 comparability, moderate was considered to have been obtained with correlations between 0.50 -

3370.69 while anything below 0.50 indicated a poor correlation between the two variables of interest

338 (Hopkins et al. 2009). Hopping data were compared to running data for all calculated variables

339 using the above criteria.

340

\section{Results}

342 Data for the left leg only are presented in Table 2 and 3 as both the right and left leg showed similar

343 results across all variables. Only the $5.0 \mathrm{~min} / \mathrm{km}(3.3 \mathrm{~m} / \mathrm{s})$ running pace was presented to keep the

344 results concise, with all speeds showing similar trends. Running at $5.0 \mathrm{~min} / \mathrm{km}$ was considered to

345 be a speed that would be encountered in training and/or racing by both elite and amateur triathletes, 
346 based on discussion with athletes, coaches and High Performance Sport New Zealand. Descriptive

347 statistics are presented in Table 2 for all variables analysed for the left leg during running (5.0

$348 \mathrm{~min} / \mathrm{km}$ ), hopping with a natural knee bend and hopping with the knee as straight as possible.

349

350 Summary of Results

351 Hopping with a straight knee resulted in a reduction in knee stiffness compared to bent knee 352 hopping (natural hopping with no instruction) to give an average value closer to running knee 353 stiffness. Ankle stiffness was lower in both hopping conditions compared to running and did not 354 significantly differ between the two hopping conditions. The combined stiffness of the hip, knee 355 and ankle was also less in straight knee hopping than running. All joint variables were closer to 356 running for straight knee than bent knee hopping. Leg stiffness was more than two-fold greater

357 when using the $\mathrm{k}_{\operatorname{leg} / \text { brake }}$ (Equation L3) estimation than for $\mathrm{k}_{\operatorname{leg} / \mathrm{dynamic}}$ (Equation L1) or $\mathrm{k}_{\operatorname{leg} / \text { time }}$ 358 (Equation L2). However, the magnitude of the $\mathrm{k}_{\operatorname{leg} / \text { brake }}$ (Equation L3) estimate was closer to the 359 combined joint stiffness. Ankle stiffness was greater than knee stiffness during running but this 360 relationship was reversed for both hopping conditions. The variation (\% of mean) of knee stiffness 361 was larger than the other two joints and this variation was greatest with straight leg hopping (60\%).

362 Variation of the stiffness measurements increased when moving from the "global" vertical 363 stiffness to the more focused joint stiffness.

*** Insert Table 2 here***

Reliability analysis

366 The reliability and measurement variability are reported in Table 3. All running vertical and leg

367 stiffness variables showed good overall reliability except for the $\mathrm{k}_{\text {leg/brake }}$ (Equation L3) estimates. 
368 Good reliability was achieved when the top of the 'true' leg was measured from the modelled hip

369 joint centre $\left(\mathrm{k}_{\text {leg/brakeHJC}}\right)$. When measured from the single trochanterion marker, overall reliability

370 was moderate. Individual joint stiffness ranged from poor to good with the hip having the poorest

371 and ankle having the best overall reliability. Combining the joints as hip, knee and ankle, hip and

372 knee or knee and ankle tended to improve the reliability to between moderate and good. For bent

373 knee hopping $\mathrm{k}_{\text {leg/time }}$ (Equation L2) and $\mathrm{k}_{\mathrm{leg} / \text { brakeGTR }}$ (Equation L3) methods showed good

374 reliability, with all other leg stiffness measures showing only moderate reliability. All joint

375 stiffness estimates, including joint combinations had poor overall reliability for bent knee hopping.

376 Straight leg hopping improved the $\mathrm{k}_{\operatorname{leg} / \mathrm{dynamic}}$ (Equation L1) estimate reliability but gave only poor

377 to moderate $\mathrm{k}_{\operatorname{leg} / \text { brake }}$ (Equation L3) reliability. Overall reliability of the ankle was improved with 378 straight leg hopping.

*** Insert Table 3 here***

380 Comparing hoping and running stiffness

381 Stiffness during hopping with the straight and bent knee condition were compared with the related

382 running stiffness measurement (Table 4). Comparability of hopping and running stiffness was poor

383 for all joint measures (Equation $\mathrm{J}$ ) when hopping with a bent knee except the ankle which was

384 moderate. All leg stiffness measures for straight knee hopping had poor comparability with

385 running. Moderate comparability was achieved between bent knee hopping and running for all leg

386 measurements except $\mathrm{k}_{\text {leg/brakeGTR }}$ (Equation L3) which was poor. Conversely, comparisons

387 between straight knee hopping and running were moderate for the individual knee and ankle

388 (Equation J), hip+knee (Equation 2) and sumjoints (Equation 1) and large for knee+ankle

389 (Equation 3). Only the hip was poorly correlated with running. 
391 Comparing leg stiffness with vertical and joint stiffness

392 As the middle level of stiffness, leg stiffness estimates were compared with vertical and joint

393 stiffness estimates (Table 5). The highest correlation with each of the combinations of joints,

394 sumjoints (Equation 1), hip+knee (Equation 2), knee+ankle (Equation 3) $(r=0.61, r=0.66, r=0.82)$

395 was with $\mathrm{k}_{\text {leg/time }}$ (Equation L2). Confidence limits for all joint measurement correlations were

396 large, with this variation smallest between $\mathrm{k}_{\text {knee+ankle }}$ (Equation 2) and $\mathrm{k}_{\mathrm{leg} / \mathrm{time}}$ (Equation L2). The

397 time (Equation L2) and dynamic (Equation L1) methods had large correlations with knee stiffness

398 (Equation J), however ankle and hip stiffness alone showed poor correlations with leg stiffness.

399 All $\mathrm{k}_{\text {leg }}$ estimates had large correlations with both $\mathrm{k}_{\mathrm{vert} / \text { dynamic }}\left(\right.$ Equation V1) and $\mathrm{k}_{\mathrm{vert} / \text { time }}$ (Equation $400 \mathrm{~V} 2)$.

\section{Discussion}

404 Understanding the mechanism of overuse injuries is confounded by the insidious nature of the 405 injury with lack of a single defining injurious event. Biomechanical research into injuries has 406 tended to focus on individual joints or muscles to isolate risk factors for injuries. It is possible that 407 it is the interaction between multiple segments and structures within the kinetic chain that results 408 in progressive disruption of the structure and function resulting in overuse injuries (Lorimer \& 409 Hume 2014). The various levels of stiffness allow measurement of this interaction and may provide

410 a useful first step in the analysis of the injury process for overuse injuries such as Achilles tendon 411 injuries. 
412 Analysis of joint stiffness gives greater information regarding the mechanics of the lower limb,

413 however the poor reliability of isolated joint stiffness estimates (Joseph et al. 2013) has currently

414 limited the usefulness of such measures. Compression of the 'leg spring' is achieved through

415 rotation of the joints and therefore joint stiffness should be related to leg stiffness. The contribution

416 of each joint to the overall leg stiffness needs to be established to understand how triathletes and

417 other athletes adjust stiffness in response to changes in task or environment constraints. The use

418 of hopping as a surrogate for running would limit the space and equipment requirements, however,

419 the correlation between hopping stiffness and running stiffness first needs to be established in a

420 variety of populations.

421

422 Mean $\mathrm{k}_{\mathrm{vert} / \mathrm{dynamic}}$ (Equation V1) was similar to results reported for treadmill running (Dutto \& 423 Smith 2002). When contact and flight time were used to estimate vertical stiffness $\left(\mathrm{k}_{\mathrm{vert} / \text { time, }}\right.$ 424 Equation V2), stiffness was similar to $\mathrm{k}_{\mathrm{vert} / \text { dynamic }}$ (Equation V1) but substantially smaller than the 425 average stiffness reported by Hunter et al. (2007) using the same time based calculation method. 426 The lower stiffness in the current research could be the result of using different populations: 427 competitive triathletes versus general runners. Alternatively, use of a measured leg length, in the 428 current data, rather than estimated leg length could account for the differences in stiffness reported. 429 Running speed was also different for each individual in the runners assessed by Hunter et. al. 430 (2007) which may further contribute to these between study differences population which 431 influences the vertical stiffness estimates (Brughelli \& Cronin 2008; Hunter \& Smith 2007).

433 Mean $\mathrm{k}_{\text {leg/dynamic }}\left(\right.$ Equation L1) and $\mathrm{k}_{\text {leg/time }}($ Equation L2) for the triathletes were similar to results 434 for treadmill running (Dutto \& Smith 2002; Hunter \& Smith 2007) but were lower than for 
435 overground running for the respective calculations (Arampatzis et al. 1999; Coleman et al. 2012).

436 Treadmill running tends to be more upright with a shorter stride, higher cadence and flatter foot

437 contact than over ground running (Nigg et al. 1995; Riley et al. 2008). Increased cadence is

438 associated with increased $\mathrm{k}_{\operatorname{leg}}$ (Dutto \& Smith 2002; Farley \& Gonzalez 1996; Girard et al. 2011;

439 Girard et al. 2013). However, reducing the contact angle of the stance leg may contribute to lower

$440 \mathrm{k}_{\operatorname{leg}}$ (Seyfarth et al. 2002; Seyfarth et al. 2003). Alternately, the requirements of landing on a force

441 platform in overground running also introduces the issue of targeting which could alter joint angles

442 and landing forces at contact, contributing to some difference in stiffness estimates than what

443 would have occurred naturally in over ground running gait (Challis 2001). Joseph et al. (2013)

444 reported lower $\mathrm{k}_{\mathrm{leg} / \mathrm{dynamic}}$ (Equation L1) than the current data for over ground running in middle

445 distance runners. Due to the small sample sizes in the present study and those studies reported

446 above, population differences would alter the mean stiffness estimates (Hopkins 2006). While

447 triathletes do not have significantly different running motor coordination compared to training

448 matched runners, differences are observed between triathletes and novice runners (Chapman et al.

449 2008). Comparisons between cohorts from various sporting populations and triathletes could

450 therefore explain the between study differences in $\mathrm{k}_{\mathrm{leg}}$ observed.

451

452 Average $\mathrm{k}_{\text {ankle }}$ (Equation $\mathrm{J}$ ) for the current data was similar to results for sprint running (Kuitunen 453 et al. 2002), but about half the stiffness of over ground running at a similar horizontal velocity

454 (Joseph et al. 2013). The majority of literature reports knee stiffness to be higher than ankle 455 stiffness in over ground running (Joseph et al. 2013; Kuitunen et al. 2002). The current cohort of 456 triathletes showed equal group means for ankle and knee stiffness with many individual triathletes

457 having lower knee than ankle stiffness. A similar relationship between $\mathrm{k}_{\mathrm{knee}}$ and $\mathrm{k}_{\text {ankle }}$ (Equation $\mathrm{J}$ ) 
458 was reported for thirteen runners, running over ground at a range of velocities (Arampatzis et al.

459 1999). The footstrike pattern was not controlled in the current study's cohort of triathletes. A

460 higher ratio of midfoot and forefoot strikers in the subject population is likely to increase the

461 average knee stiffness and decrease average ankle stiffness (Laughton et al. 2003). Sprint running

462 uses a predominantly forefoot strike, which could explain the similar joint stiffness between

463 triathletes and sprinters despite different horizontal velocities (Kuitunen et al. 2002). However,

464 further investigation into the relationship between knee and ankle stiffness and how inter-

465 individual variation in factors like footstrike patterns influences this relationship is required.

466

467 The results, of the present study confirmed that vertical and leg stiffness have good inter-day 468 reliability during running. Individual joint stiffness ranged from poor to good. While the 469 measurement reliability (MDiff\% and ES) were acceptable for ankle, knee and hip, the knee and 470 hip had large measurement variability $(\% \mathrm{CV}$ and $\mathrm{ICC})$. When the joints were combined as

471 sumjoints (Equation 1), hip +knee (Equation 2) or knee+ankle (Equation 3), variability was

472 reduced to an acceptable level and overall reliability was improved to moderate to good. This result

473 highlights the important role that regulation of joint stiffness holds in the co-ordination of lower 474 body segemnts to achieve a task goal (Davids et al. 2008; Hamill et al. 2012).

475

476 Stiffness control is initiated prior to ground contact with muscle pre-activation. The hip primarily

477 controls the angle of the leg at contact and therefore the angle of the sweep of the leg. Less hip

478 flexion would result in the centre of pressure at initial contact being closer to the centre of mass

479 (Figure 1), a smaller angle of the sweep of the leg and as a result less 'leg spring' compression, if 480 all other factors remain equal. The knee allows adaptation to the environment following contact 
481 and therefore has greater variation than the hip and ankle (Lafortune et al. 1996). The current

482 results support control of the kinetic chain in this manner. Correlations of the hip and knee 483 combination $(\mathrm{r}=0.66)$ (Equation 2$)$ and the three joints combined ( $\mathrm{r}=0.61)$ (Equation 1) with $\mathrm{k}_{\text {leg }}$ time

484 (Equation L2) were lower than for the knee and ankle combination ( $\mathrm{r}=0.82 ; 95 \%$ CI $0.52-0.94)$

485 (Equation 3). Knee correlation with $\mathrm{k}_{\operatorname{leg} / \text { time }}(\mathrm{r}=0.79 ; 95 \% \mathrm{CI} 0.46-0.93)$ (Equation L2) was similar 486 to the knee and ankle combination (Equation 3) indicating that the knee is the primary controller 487 of leg stiffness of triathletes running at the velocities assessed in the present study.

489 The current data suggests that in triathletes, hopping at $2.2 \mathrm{~Hz}$, either with normal knee bend or a 490 straight knee, does not correlate well with treadmill running for leg and joint stiffness estimates. 491 Interestingly, bent knee hopping correlates moderately with running for leg stiffness but straight 492 knee hopping has better correlations than bent knee for joint stiffness. Gait has been divided into 493 two models based on the trajectory of the centre of mass, the 'inverted pendulum' for walking 494 (Mochon \& McMahon 1980) and 'bouncing/spring-mass' for running (Blickhan 1989; Cavagna 495 \& Kaneko 1977; McMahon \& Cheng 1990). Like running, the centre of mass trajectory during 496 hopping is lowest at the time point of highest vertical force and highest at mid-flight. However, 497 projecting the centre of mass forward during running necessitates different muscle activity with 498 changes in the electromyography profiles compared to vertical jumps or hops (Mero \& Komi 499 1994). During straight knee hopping, the ankle is the dominant joint controlling stiffness resulting 500 in similar stiffness between the knee and ankle. Extending the leg anterior to the centre of mass 501 during running results in a relatively small knee flexion compared to bent knee hopping (Farley \& 502 Morgenroth 1999; Ferber et al. 2003) which could explain the better match for knee stiffness 503 between straight knee hopping and running. Bent knee hopping however, is a more natural 
504 example of how all the tissues of the lower limb work together to absorb the impact of landing.

505 Leg stiffness is a measure of this interaction within the lower limb system, which could explain

506 the improved correlation between the running and bent knee hopping for leg stiffness.

507

508 Besides biomechanical differences in the task demands between hopping and running, the poor

509 stiffness correlations between these two tasks could be due to the lack of familiarisation the

510 triathletes had for hopping. It should also be noted that stiffness is altered as a result of changing

511 contact time (Girard et al. 2011; Girard et al. 2013; Hobara et al. 2007; Hoffrén et al. 2011; Morin

512 et al. 2007). Therefore, the hop or stride frequency would also influence stiffness and the potential

513 relationships between stiffness as measured during hopping and running. In a one hour fatiguing

514 run, runners' preferred stride frequency ranged from 1.36 to $1.60 \mathrm{~Hz}$ (Hunter \& Smith 2007). It is

515 possible that hopping would provide more comparable stiffness estimates if the triathletes in the

516 current study hopped at their preferred stride frequency. The study population contained a mixture

517 of rearfoot and midfoot strike running patterns, based on presence or absence of a contact peak in

518 the vertical ground reaction force, which may have also confounded the comparison between

519 hopping and running. During hopping, landing generally occurs on the forefoot and therefore

520 would be more likely to mimic a forefoot strike during running. The ankle angle profile of a

521 rearfoot strike runner shows an initial plantarflexion action followed by dorsiflexion, which is not

522 apparent in forefoot runners (Williams III et al. 2000). Future research should therefore look to

523 separate the rearfoot and forefoot runners and/or assess stiffness as fractions of the first half of

524 stance to determine whether this may provide better insight into the correlations between hopping

525 and running in different sub-populations of running athletes. 


\section{Conclusion}

527 Due to the superior reliability and correlations with both combinations of joint stiffness and

528 vertical stiffness, the $\mathrm{k}_{\text {leg/time }}$ (Equation L2) method is recommended for assessing leg stiffness.

529 However, $\mathrm{k}_{\text {leg/dynamic }}$ (Equation V2) also appears to be a good measure and when combined with

530 joint angle recording also allows for calculation of joint stiffness. Joints should be assessed as a

531 system in relation to each other rather than in isolation to gain acceptable reliability of the measure.

532 The knee and ankle combination appears to be the most important when assessing changes in leg

533 stiffness for triathletes running at the paces assessed in the present study. Hopping at $2.2 \mathrm{~Hz}$ is not

534 a good substitute for running when estimating stiffness in triathletes. Further analysis is required

535 to determine if hopping correlates with running when frequency is constrained to the triathletes

536 preferred stride rate or assessed in sub-groups of athletes who differ on their foot strike patterns or

537 familiarity with vertical hopping.

\section{References}

Abt JP, Sell TC, Chu Y, Lovalekar M, Burdett RG, and Lephart SM. 2011. Running Kinematics and Shock Absorption Do Not Change After Brief Exhaustive Running. The Journal of Strength and Conditioning Research 25:1479-1485. 10.1519/JSC.0b013e3181ddfcf8

541

542

543

Arampatzis A, Bruggemann GP, and Metzler V. 1999. The effect of speed on leg stiffness and joint kinetics in human running. Journal of Biomechanics 32:1349-1353.

Bartlett R, Wheat J, and Robins M. 2007. Is movement variability important for sports biomechanists? Sports Biomechanics 6:224-243. 10.1080/14763140701322994

Belli A, Bui P, Berger A, Geyssant A, and Lacour J-R. 2001. A treadmill ergometer for threedimensional ground reaction forces measurement during walking. Journal of Biomechanics 34:105-112.

Besier TF, Sturnieks DL, Alderson JA, and Lloyd DG. 2003. Repeatability of gait data using a functional hip joint centre and a mean helical knee axis. Journal of Biomechanics 36:1159-1168.

Blickhan R. 1989. The spring-mass model for running and hopping. Journal of Biomechanics 22:1217-1227.

Bradshaw E, Hume P, Calton M, and Aisbett B. 2010. Reliability and variability of day-to-day vault training measures in artistic gymnastics. Sports Biomechanics 9:79-97.

Brughelli M, and Cronin J. 2008. Influence of running velocity on vertical, leg and joint stiffness. Sports Medicine 38:647-657. 
558

559

560

561

562

563

564

565

566

567

568

569

570

571

572

573

574

575

576

577

578

579

580

581

582

583

584

585

586

587

588

589

590

591

592

593

594

595

596

597

598

599

600

601

602

Butler RJ, Crowell III HP, and Davis IM. 2003. Lower extremity stiffness: Implications for performance and injury. Clinical Biomechanics 18:511-517.

Cavagna GA, and Kaneko M. 1977. Mechanical work and efficiency in level walking and running. Journal of Physiology 268:467-481.

Challis JH. 2001. The variability in running gait caused by force plate targeting. Journal of Applied Biomechanics 17:77-83.

Chapman AR, Vicenzino B, Blanch P, Dowlan S, and Hodges PW. 2008. Does cycling effect motor coordination of the leg during running in elite triathletes? Journal of Science \& Medicine in Sport 11:371-380.

Chelly SM, and Denis C. 2001. Leg power and hopping stiffness: Relationship with sprint running performance. Medicine \& Science in Sports \& Exercise 33:326-333.

Coleman DR, Cannavan D, Horne S, and Blazevich AJ. 2012. Leg stiffness in human running: Comparison of estimates derived from previously published models to direct kinematickinetic measures. Journal of Biomechanics 45:1987-1991.

Dalleau G, Belli A, Bourdin M, and Lacour J-R. 1998. The spring-mass model and the energy cost of treadmill running. European Journal of Applied Physiology and Occupational Physiology 77:257-263. 10.1007/s004210050330

Dalleau G, Belli A, Viale F, Lacour J, and Bourdin M. 2004. A simple method for field measurements of leg stiffness in hopping. International Journal of Sports Medicine 25:170-176.

Davids K, Button C, and Bennett S. 2008. Physical constraints on coordination: Dynamical systems theory. Dynamics of skill acquisition: A constraints-led approach. Champaign, IL: Human Kinetics, 29-53.

Diggin D, Anderson R, and Harrison AJ. 2016. An examination of the true reliability of lower limb stiffness measures during overground hopping. Journal of Applied Biomechanics 32:278-286.

Dutto DJ, and Smith GA. 2002. Changes in spring-mass characteristics during treadmill running to exhaustion. Medicine \& Science in Sports \& Exercise 34:1324-1331.

Farley CT, Blickhan R, Saito J, and Taylor CR. 1991. Hopping frequency in humans: A test of how springs set stride frequency in bouncing gaits. Journal of Applied Physiology 71:2127-2132.

Farley CT, and Gonzalez O. 1996. Leg stiffness and stride frequency in human running. Journal of Biomechanics 29:181-186.

Farley CT, and Morgenroth DC. 1999. Leg stiffness primarily depends on ankle stiffness during human hopping. Journal of Biomechanics 32:267-273.

Ferber R, McClay Davis I, and Williams Iii DS. 2003. Gender differences in lower extremity mechanics during running. Clinical Biomechanics 18:350-357.

Girard O, Micallef J, and Millet GP. 2011. Changes in spring-mass model characteristics during repeated running sprints. European Journal of Applied Physiology 111:125-134.

Girard O, Millet GP, Slawinski J, Racinais S, and Micallef JP. 2013. Changes in running mechanics and spring-mass behaviour during a 5-km time trial. International Journal of Sports Medicine 34:832-840.

Granata KP, Padua DA, and Wilson SE. 2002. Gender differences in active musculoskeletal stiffness. Part II. Quantification of leg stiffness during functional hopping tasks. Journal of Electromyography and Kinesiology 12:127-135. 
603 Günther M, and Blickhan R. 2002. Joint stiffness of the ankle and the knee in running. Journal of

604 Biomechanics 35:1459-1474. http://dx.doi.org/10.1016/S0021-9290(02)00183-5

605

606

607

608

609

610

611

612

613

614

615

616

617

618

619

620

621

622

623

624

625

626

627

628

629

630

631

632

633

634

635

636

637

638

639

640

641

642

643

644

645

646

647

Hamill J, Palmer C, and Van Emmerik RE. 2012. Coordinative variability and overuse injury. Sports Medicine, Arthroscopy, Rehabilitation, Therapy and Technology 4:45.

Hiley MJ, Zuevsky VV, and Yeadon MR. 2013. Is skilled technique characterized by high or low variability? An analysis of high bar giant circles. Human Movement Science 32:171-180.

Hobara H, Kanosue K, and Suzuki S. 2007. Changes in muscle activity with increase in leg stiffness during hopping. Neuroscience Letters 418:55-59.

Hoffrén M, Ishikawa M, Rantalainen T, Avela J, and Komi PV. 2011. Age-related muscle activation profiles and joint stiffness regulation in repetitive hopping. Journal of Electromyography and Kinesiology 21:483-491.

Hopkins WG. 2000. Measures of reliability in sports medicine and science. Sports Medicine $30: 1-15$.

Hopkins WG. 2006. Estimating Sample Size for Magnitude-Based Inferences. Sportscience 10:63-70.

Hopkins WG, Marshall SW, Batterham AM, and Hanin J. 2009. Progressive statistics for studies in sports medicine and exercise science. Medicine \& Science in Sports \& Exercise 41:313.

Hunter I, and Smith GA. 2007. Preferred and optimal stride frequency, stiffness and economy: Changes with fatigue during a 1-h high-intensity run. European Journal of Applied Physiology 100:653-661.

Joseph CW, Bradshaw EJ, Kemp J, and Clark RA. 2013. The interday reliability of ankle, knee, leg, and vertical musculoskeletal stiffness during hopping and overground running. Journal of Applied Biomechanics 29:386-394.

Kannus P. 1997. Etiology and pathophysiology of chronic tendon disorders in sports. Scandinavian Journal of Medicine and Science in Sports 7:78-85.

Kluitenberg B, Bredeweg SW, Zijlstra S, Zijlstra W, and Buist I. 2012. Comparison of vertical ground reaction forces during overground and treadmill running. A validation study. BMC Musculoskeletal Disorders 13:235.

Kuitunen S, Komi PV, and Kyrolainen H. 2002. Knee and ankle joint stiffness in sprint running. Medicine \& Science in Sports \& Exercise 34:166-173.

Lafortune MA, Hennig EM, and Lake MJ. 1996. Dominant role of interface over knee angle for cushioning impact loading and regulating initial leg stiffness. Journal of Biomechanics 29:1523-1529. http://dx.doi.org/10.1016/S0021-9290(96)80003-0

Laughton CA, Davis IMC, and Hamill J. 2003. Effect of strike pattern and orthotic intervention on tibial shock during running. Journal of Applied Biomechanics 19:153-168.

Liew B, Netto K, and Morris S. 2017. Increase in leg stiffness reduces joint work during backpack carriage running at slow velocities. Journal of Applied Biomechanics 33:347353.

Lorimer AV, and Hume PA. 2014. Achilles tendon injury risk factors associated with running. Sports Medicine 44:1459-1472. 10.1007/s40279-014-0209-3

Lorimer AV, and Hume PA. 2016. Stiffness as a risk factor for achilles tendon injury in running athletes. Sports Medicine 46:1921-1938.

McMahon TA, and Cheng GC. 1990. The mechanics of running: How does stiffness couple with speed? Journal of Biomechanics 23:65-78. 
648

649

650

651

652

653

654

655

656

657

658

659

660

661

662

663

664

665

666

667

668

669

670

671

672

673

674

675

676

677

678

679

680

681

682

683

684

685

686

687

688

689

690

691

692

Mero A, and Komi PV. 1994. EMG, force, and power analysis of sprint-specific strength exercises. Journal of Applied Biomechanics 10:1-13.

Mochon S, and McMahon TA. 1980. Ballistic walking. Journal of Biomechanics 13:49-57. http://dx.doi.org/10.1016/0021-9290(80)90007-X

Morgan DW, Martin PE, Krahenbuhl GS, and Baldini FD. 1991. Variability in running economy and mechanics among trained male runners. Med Sci Sports Exerc 23:378-383.

Morin JB, Dalleau G, Kyrolainen H, Jeannin T, and Belli A. 2005. A simple method for measuring stiffness during running. Journal of Applied Biomechanics 21:167-180.

Morin JB, Samozino P, Zameziati K, and Belli A. 2007. Effects of altered stride frequency and contact time on leg-spring behavior in human running. Journal of Biomechanics 40:33413348. http://dx.doi.org/10.1016/j.jbiomech.2007.05.001

Nigg BM, De Boer RW, and Fisher V. 1995. A kinematic comparison of overground and treadmill running. Medicine \& Science in Sports \& Exercise 27:98-105.

Oliver JL, and Smith PM. 2010. Neural control of leg stiffness during hopping in boys and men. Journal of Electromyography and Kinesiology 20:973-979.

Piazza SJ, Okita N, and Cavanagh PR. 2001. Accuracy of the functional method of hip joint center location: Effects of limited motion and varied implementation. Journal of Biomechanics 34:967-973.

Pruyn EC, Watsford ML, and Murphy AJ. 2016. Validity and reliability of three methods of stiffness assessment. Journal of Sport and Health Science 5:476-483.

Riley PO, Dicharry J, Franz J, Croce UD, Wilder RP, and Kerrigan DC. 2008. A kinematics and kinetic comparison of overground and treadmill running. Medicine \& Science in Sports \& Exercise 40:1093-1100.

Rummel J, Iida F, Smith JA, and Seyfarth A. 2008. Enlarging regions of stable running with segmented legs. IEEE International Conference on Robotics and Automation, 2008 Pasadena, CA: IEEE. p 367-372.

Seyfarth A, Geyer H, Günther M, and Blickhan R. 2002. A movement criterion for running. Journal of Biomechanics 35:649-655. http://dx.doi.org/10.1016/S0021-9290(01)00245-7

Seyfarth A, Geyer H, and Herr H. 2003. Swing-leg retraction: A simple control model for stable running. Journal of Experimental Biology 206:2547-2555. 10.1242/jeb.00463

Silder A, Heiderscheit B, and Thelen DG. 2008. Active and passive contributions to joint kinetics during walking in older adults. Journal of Biomechanics 41:1520-1527.

Stergiou N, and Decker LM. 2011. Human movement variability, nonlinear dynamics, and pathology: Is there a connection? Human Movement Science 30:869-888. https://doi.org/10.1016/j.humov.2011.06.002

Stewart A, Marfell-Jones M, Olds T, and de Ridder H. 2011. International standards for anthropometric assessment. Lower Hutt, New Zealand: International Society for the Advancement of Kinanthropometry.

Strocchi R, De Pasquale V, Guizzardi S, Govoni P, Facchini A, Raspanti M, Girolami M, and Giannini S. 1991. Human Achilles tendon: Morphological and morphometric variations as a function of age. Foot \& Ankle International 12:100-104.

Tulchin K, Orendurff M, and Karol L. 2010. A comparison of multi-segment foot kinematics during level overground and treadmill walking. Gait \& Posture 31:104-108.

Whiteside D, Elliott BC, Lay B, and Reid M. 2015. Coordination and variability in the elite female tennis serve. Journal of Sports Sciences 33:675-686. 
693 Williams III DS, McClay IS, and Manal KT. 2000. Lower extremity mechanics in runners with a 694 converted forefoot strike pattern. Journal of Applied Biomechanics 16:210-218.

695 Winter DA. 1980. Overall principle of lower limb support during stance phase of gait. Journal of 696 Biomechanics 13:923-927. http://dx.doi.org/10.1016/0021-9290(80)90162-1

697 Winter DA. 1984. Kinematic and kinetic patterns in human gait: variability and compensating $698 \quad$ effects. Human Movement Science 3:51-76.

699 
Figure 1

Biomechanical stiffness models

a. McMahon and Cheng's ( 1990 ) spring-mass model for vertical and leg stiffness (McMahon \& Cheng 1990 ) ( McMahon \& Cheng 1990 ) ; b. Coleman et al. ( 2012 ) true leg stiffness model; c. Joint stiffness model ( Blickhan 1989 ; Farley \& Morgenroth 1999 ) .

A

B

$\mathrm{C}$
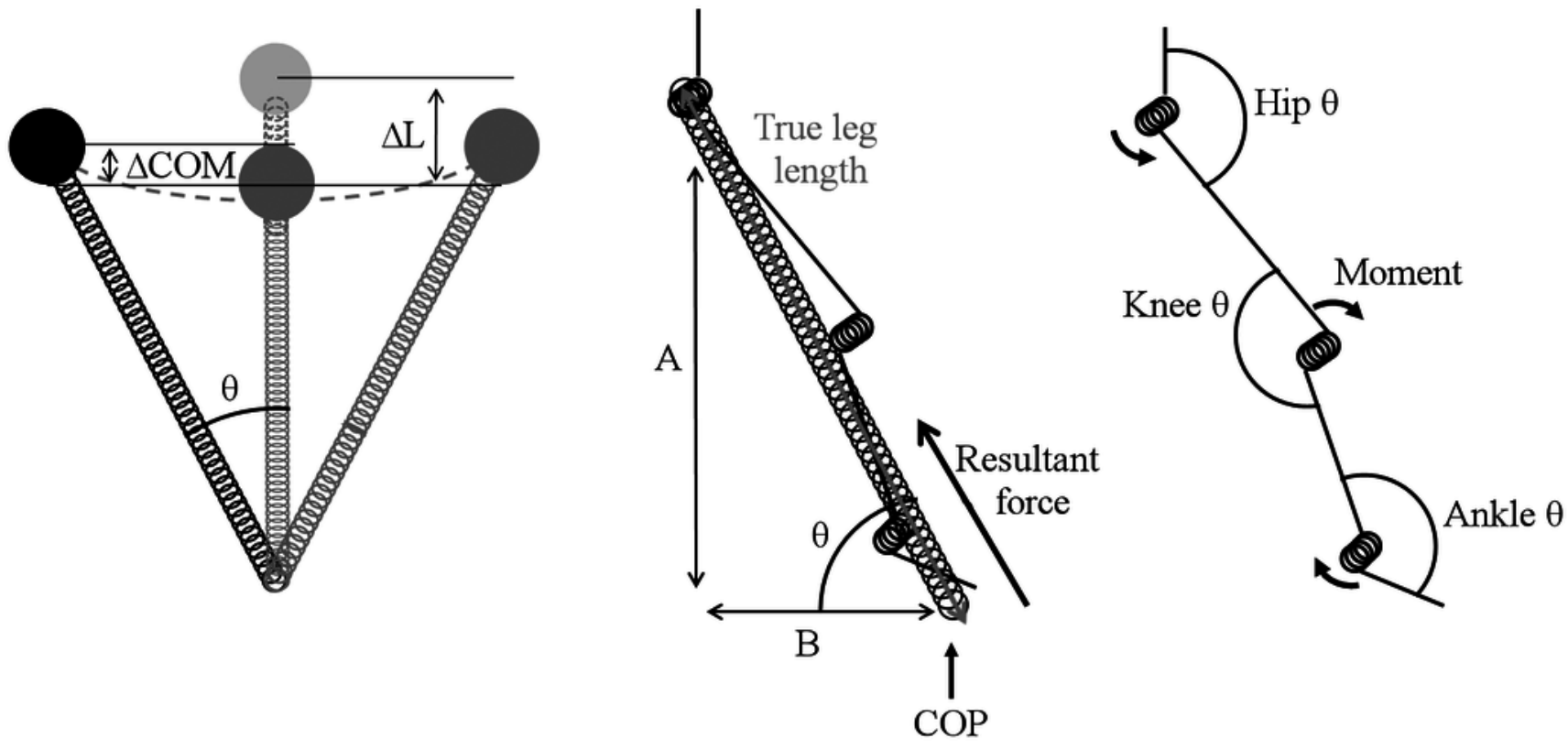


\section{Figure 2}

Lower body marker locations without and with tracking clusters.

Photo Credit: Prof. Patria Hume

*Note: Auto Gamma Correction was used for the image. This only affects the reviewing manuscript. See original source image if needed for review.

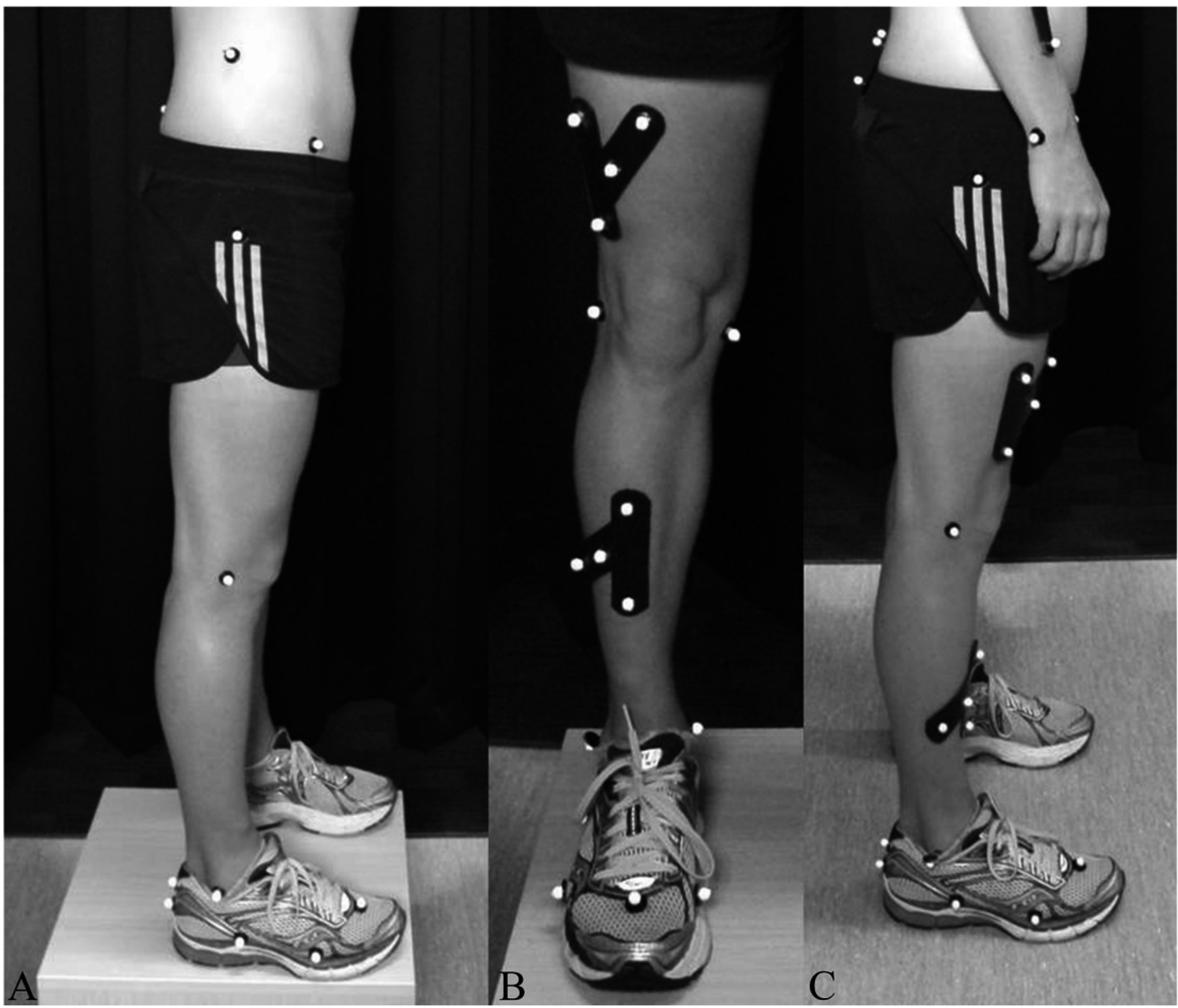




\section{Table $\mathbf{1}$ (on next page)}

Biomechanical stiffness model calculations, variables and equipment. 
1 Biomechanical stiffness model calculations, variables and equipment.

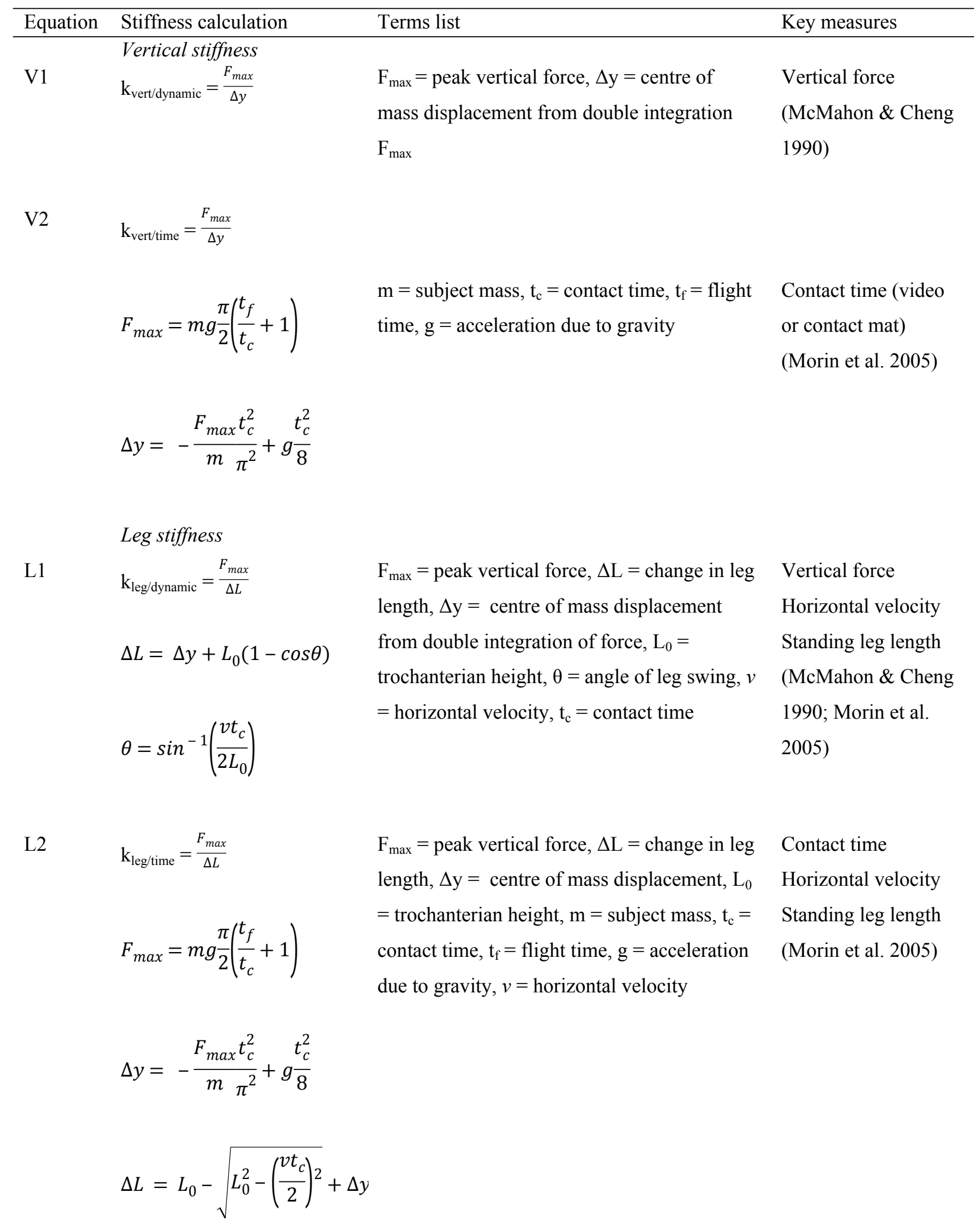


L3

$$
\begin{aligned}
& k_{\text {leg } / \text { brake }}=\frac{\max F_{\text {leg }}}{\Delta L_{\text {true }}} \\
& F_{\text {leg }=\cos \left(\theta_{\text {leg }}\right) F_{R}} \\
& F_{R}=\sqrt{\left(F_{v}^{2}+F_{H}^{2}\right)} \\
& \theta_{\text {leg }}=\left(90-\theta_{\text {true }}\right)-\theta_{R} \\
& \theta_{R}=\cos ^{-1}\left(\frac{F_{v}}{F_{R}}\right) \\
& \theta_{\text {true }}=\tan ^{-1}\left(\frac{A}{B}\right)
\end{aligned}
$$

$\max F_{\text {leg }}=$ maximal force directed in line of

the leg, $\Delta \mathrm{L}_{\text {true }}=$ true change in leg length, $\theta_{\text {leg }}$

$=$ angle of leg, $F_{R}=$ resultant force, $F_{V}=$ vertical force, $\mathrm{F}_{\mathrm{H}}=$ horizontal force, $\theta_{\text {true }}=$ angle between the calculated $\mathrm{L}_{\text {true }}$ and

Horizontal force

Vertical force

horizontal axis, $\theta_{R}=$ angle of the resultant

force, $A=$ vertical distance from hip marker

to ground, $\mathrm{B}=$ horizontal distance from hip

marker to centre of pressure

\section{Joint stiffness}

J1

$$
k_{\text {joint }}=\frac{\Delta M}{\Delta \theta}
$$

$\Delta \mathrm{M}=$ change in joint moment, $\Delta \theta=$ change in joint angle
High speed video

Hip marker

Centre of pressure

(Coleman et al. 2012)
Three dimensional

force

Lower body video for inverse dynamics calculation (Farley \& Morgenroth 1999;

Günther \& Blickhan 2002) 


\section{Table 2 (on next page)}

Average stiffness for running and hopping tasks in triathletes 
1 Average stiffness for running and hopping tasks in triathletes

\begin{tabular}{|c|c|c|c|c|c|}
\hline Method & Mean $( \pm S D)$ & Method & Mean $( \pm S D)$ & Method & Mean $( \pm S D)$ \\
\hline \multicolumn{2}{|c|}{ Vertical-Run $(\mathrm{kN} / \mathrm{m} / \mathrm{kg})$} & \multicolumn{2}{|c|}{ Leg-Run $(\mathrm{kN} / \mathrm{m} / \mathrm{kg})$} & \multicolumn{2}{|c|}{ Joint-Run $\left(\mathrm{Nm} /{ }^{\circ} / \mathrm{kg}\right)$} \\
\hline $\mathrm{k}_{\mathrm{ver} / \text { dynamic }}$ & $0.34 \pm 0.06$ & $\mathrm{k}_{\text {leg/brakeHJC }}$ & $0.40 \pm 0.10$ & $\mathrm{k}_{\text {sumjoints }}$ & $0.47 \pm 0.10$ \\
\hline \multirow[t]{19}{*}{$\mathrm{k}_{\text {vert/time }}$} & $0.36 \pm 0.05$ & $\mathrm{k}_{\text {leg/brakeGTR }}$ & $0.40 \pm 0.11$ & $\mathrm{k}_{\text {ankle+knee }}$ & $0.26 \pm 0.05$ \\
\hline & & $\mathrm{k}_{\text {leg/dynamic }}$ & $0.15 \pm 0.03$ & $\mathrm{k}_{\text {hip+knee }}$ & $0.33 \pm 0.08$ \\
\hline & & $\mathrm{k}_{\text {leg/time }}$ & $0.15 \pm 0.02$ & $\mathrm{k}_{\text {ankle }}$ & $0.14 \pm 0.03$ \\
\hline & & & & $\mathrm{k}_{\mathrm{knee}}$ & $0.11 \pm 0.04$ \\
\hline & & & & $k_{\text {hip }}$ & $0.21 \pm 0.07$ \\
\hline & & $\begin{array}{l}\text { Vertical/Leg- } \\
(\mathrm{kN} / \mathrm{m} / \mathrm{kg})\end{array}$ & ent Hop & Joint-Bent & op $\left(\mathrm{Nm} /{ }^{\circ} / \mathrm{kg}\right)$ \\
\hline & & $\mathrm{Hk}_{\text {leg/brakeHJC }}$ & $0.23 \pm 0.03$ & $\mathrm{Hk}_{\text {sumjoints }}$ & $0.51 \pm 0.27$ \\
\hline & & $\mathrm{Hk}_{\text {leg/brakeGTR }}$ & $0.23 \pm 0.03$ & $\mathrm{Hk}_{\text {ankle+knee }}$ & $0.41 \pm 0.22$ \\
\hline & & $\mathrm{Hk}_{\text {leg/dynamic }}$ & $0.21 \pm 0.04$ & $\mathrm{Hk}_{\text {hip+knee }}$ & $0.45 \pm 0.22$ \\
\hline & & $\mathrm{Hk}_{\text {leg/time }}$ & $0.22 \pm 0.02$ & $\mathrm{Hk}_{\mathrm{ankle}}$ & $0.10 \pm 0.01$ \\
\hline & & & & $\mathrm{Hk}_{\mathrm{knee}}$ & $0.17 \pm 0.06$ \\
\hline & & & & $\mathrm{Hk}_{\text {hip }}$ & $0.31 \pm 0.18$ \\
\hline & & $\begin{array}{l}\text { Vertical/Leg- } \\
(\mathrm{kN} / \mathrm{m} / \mathrm{kg})\end{array}$ & traight Hop & $\begin{array}{l}\text { Joint-Strai } \\
\left(\mathrm{Nm} /{ }^{\circ} / \mathrm{kg}\right)\end{array}$ & Hop \\
\hline & & $\mathrm{Hk}_{\text {leg/brakeHJC }}$ & $0.24 \pm 0.02$ & $\mathrm{Hk}_{\text {sumjoints }}$ & $0.43 \pm 0.14$ \\
\hline & & $H k_{\text {leg/brakeGTR }}$ & $0.23 \pm 0.02$ & $\mathrm{Hk}_{\text {ankle+knee }}$ & $0.22 \pm 0.06$ \\
\hline & & $\mathrm{Hk}_{\text {leg/dynamic }}$ & $0.22 \pm 0.03$ & $\mathrm{Hk}_{\text {hip+knee }}$ & $0.33 \pm 0.12$ \\
\hline & & $\mathrm{Hk}_{\text {leg/time }}$ & $0.23 \pm 0.02$ & $\mathrm{Hk}_{\text {ankle }}$ & $0.10 \pm 0.03$ \\
\hline & & & & $\mathrm{Hk}_{\text {knee }}$ & $0.13 \pm 0.04$ \\
\hline & & & & $\mathrm{Hk}_{\text {hip }}$ & $0.20 \pm 0.10$ \\
\hline
\end{tabular}

2 


\section{Table 3(on next page)}

Summary of reliability results with $90 \%$ confidence interval for various biomechanical stiffness models for running and hopping tasks in triathletes

* $=$ at least one reliability parameter was unclear (confidence interval spanned more than one criteria). 
1 Summary of reliability results with $90 \%$ confidence interval for various biomechanical stiffness

2 models for running and hopping tasks in triathletes.

\begin{tabular}{|c|c|c|c|c|c|}
\hline \multirow[b]{2}{*}{ Method } & \multicolumn{2}{|c|}{ Reliability } & \multicolumn{2}{|c|}{ Variability } & \multirow{2}{*}{$\begin{array}{c}\text { Overall } \\
\text { Reliability }\end{array}$} \\
\hline & Mdiff $\%$ & ES & $\mathrm{CV} \%$ & $\mathrm{ICC}$ & \\
\hline \multicolumn{6}{|c|}{ Running - Vertical } \\
\hline $\mathrm{k}_{\mathrm{vert} / \text { dynamic }}$ & $3.5(0.4-6.7)$ & $-0.18(-0.21--0.15)$ & $4.2(3.2-6.7)$ & $0.95(0.88-0.98)$ & Good \\
\hline $\mathrm{k}_{\mathrm{vert} / \mathrm{time}}$ & $0.1(-3.5-3.8)$ & $0.01(-0.02-0.03)$ & $5.2(3.8-8.1)$ & $0.85(0.62-0.94)$ & Good \\
\hline \multicolumn{6}{|c|}{ Running - Leg } \\
\hline $\mathrm{k}_{\text {leg/dynamic }}$ & $0.3(-1.8-2.4)$ & $-0.00(-0.01-0.01)$ & $2.8(2.0-4.4)$ & $0.98(0.93-0.99)$ & Good \\
\hline $\mathrm{k}_{\mathrm{leg} / \mathrm{time}}$ & $0.3(-1.8-2.4)$ & $-0.00(-0.01-0.01)$ & $2.8(2.0-4.4)$ & $0.98(0.93-0.99)$ & Good \\
\hline $\mathrm{k}_{\mathrm{leg} / \mathrm{HJC}}$ & $3.2(-3.7-10.5)$ & $-0.11(-0.17--0.06)$ & $9.8(4.2-15.6)$ & $0.85(0.63-0.94)$ & Good* \\
\hline $\mathrm{k}_{\mathrm{leg} / \mathrm{GTR}}$ & $-1.4(-9.2-6.9)$ & $0.13(0.09-0.18)$ & $11.8(8.7-18.8)$ & $0.77(0.46-0.91)$ & Moderate* \\
\hline \multicolumn{6}{|c|}{ Running - Joints } \\
\hline $\mathrm{k}_{\text {sumjoints }}$ & $-5.4(-10.5-0.0)$ & $0.36(0.32-0.40)$ & $7.9(5.8-12.5)$ & $0.86(0.65-0.95)$ & Moderate* \\
\hline $\mathrm{k}_{\mathrm{knee}+\text { ankle }}$ & $-3.1(-8.4-2.5)$ & $0.18(0.16-0.20)$ & $8.0(5.9-12.7)$ & $0.87(0.66-0.95)$ & Good* \\
\hline $\mathrm{k}_{\text {hip }+\mathrm{knee}}$ & $-5.8(-11.4-0.1)$ & $0.33(0.29-0.37)$ & $8.7(6.5-13.9)$ & $0.88(0.70-0.96)$ & Moderate* \\
\hline $\mathrm{k}_{\text {ankle }}$ & $-4.2(-10.2-2.3)$ & $0.31(0.30-0.33)$ & $9.3(6.9-14.8)$ & $0.75(0.42-0.90)$ & Good* \\
\hline $\mathrm{k}_{\mathrm{knee}}$ & $-1.3(-10.2-8.4)$ & $0.02(0.00-0.05)$ & $13.8(10.1-22.1)$ & $0.90(0.73-0.96)$ & Moderate \\
\hline $\mathrm{k}_{\text {hip }}$ & $-7.7(-14.8-0.0)$ & $0.43(0.41-0.46)$ & $11.6(8.5-18.5)$ & $0.83(0.59-0.94)$ & Poor* \\
\hline \multicolumn{6}{|c|}{ Bent Knee Hopping - Leg } \\
\hline $\mathrm{Hk}_{\text {leg/dynamic }}$ & $-7.0(-11.6--2.2)$ & $0.34(0.32-0.36)$ & $5.9(4.2-10.4)$ & $0.92(0.74-0.97)$ & Moderate \\
\hline $\mathrm{Hk}_{\text {leg/time }}$ & $-3.7(-6.6--0.7)$ & $0.51(0.50-0.52)$ & $3.9(2.8-6.4)$ & $0.73(0.33-0.91)$ & Good* \\
\hline $\mathrm{Hk}_{\mathrm{leg} / \mathrm{HJC}}$ & $-5.5(-10.1--0.7)$ & $0.43(0.41-044)$ & $6.3(4.5-10.5)$ & $0.79(0.45-0.93)$ & Moderate* \\
\hline $\mathrm{Hk}_{\mathrm{leg} / \mathrm{GTR}}$ & $-3.5(-7.7-0.9)$ & $0.38(0.36-0.39)$ & $5.5(4.0-9.3)$ & $0.71(0.30-0.90)$ & Good* \\
\hline \multicolumn{6}{|c|}{ Bent Knee Hopping - Joints } \\
\hline $\mathrm{Hk}_{\text {sumjoints }}$ & $-10.4(-32.2-18.5)$ & $0.03(-0.11-0.17)$ & $13.0(9.1-23.2)$ & $.52(-0.07-0.83)$ & Poor* \\
\hline $\mathrm{Hk}_{\text {hip+knee }}$ & $-10.4(-35.4-24.3)$ & $0.22(0.10-0.35)$ & $49.1(33.8-92.9)$ & $0.32(-0.28-0.72)$ & Poor* \\
\hline $\mathrm{Hk}_{\mathrm{knee}+\text { ankle }}$ & $-4.1(-32.0-35.1)$ & $0.03(-0.10-0.17)$ & $48.0(32.5-95.5)$ & $0.39(-0.23-0.78)$ & Poor* \\
\hline $\mathrm{Hk}_{\text {ankle }}$ & $-8.2(-17.5--2.1)$ & $0.56(0.55-0.57)$ & $13.0(9.1-23.2)$ & $0.52(-0.07-0.83)$ & Poor* \\
\hline $\mathrm{Hk}_{\mathrm{knee}}$ & $2.9(-18.5-29.9)$ & $-0.13(-0.17--0.08)$ & $32.9(23.1-59.7)$ & $0.51(-0.03-0.82)$ & Poor* \\
\hline $\mathrm{Hk}_{\mathrm{hip}}$ & $-31.9(-51.5--3.6)$ & $0.59(0.49-0.68)$ & $48.1(32.6-95.7)$ & $0.56(-0.03-0.85)$ & Poor* \\
\hline \multicolumn{6}{|c|}{ Straight Knee Hopping - Leg } \\
\hline $\mathrm{Hk}_{\text {leg/dynamic }}$ & $2.8(-1.9-7.7)$ & $-0.18(-0.20--0.16)$ & $5.8(4.2-9.8)$ & $0.91(0.73-0.97)$ & Good* \\
\hline $\mathrm{Hk}_{\mathrm{leg} / \mathrm{time}}$ & $1.1(-1.6-3.9)$ & $-0.14(-0.15--0.13)$ & $5.8(4.2-9.8)$ & $0.85(0.62-0.95)$ & Good* \\
\hline $\mathrm{Hk}_{\mathrm{leg} / \mathrm{HJC}}$ & $4.2(-1.5-10.2)$ & $-0.26(-0.27--0.24)$ & $7.1(5.1-12.0)$ & $0.69(0.24-0.89)$ & Moderate* \\
\hline $\mathrm{Hk}_{\mathrm{leg} / \mathrm{GTR}}$ & $6.2(0.8-11.8)$ & $-0.50(-0.51--0.48)$ & $6.5(4.7-10.9)$ & $0.69(0.25-0.89)$ & Poor* \\
\hline \multicolumn{6}{|c|}{ Straight Knee Hopping - Joints } \\
\hline $\mathrm{Hk}_{\text {sumjoints }}$ & $-2.7(-13.7-22.3)$ & $-0.08(-0.16-0.00)$ & $23.7(16.8-41.9)$ & $0.66(0.20-0.88)$ & Poor* \\
\hline $\mathrm{Hk}_{\text {hip+knee }}$ & $1.7(-17.4-23.3)$ & $-0.10(-0.17--0.02)$ & $28.9(20.4-51.9)$ & $0.63(0.15-0.87)$ & Poor* \\
\hline $\mathrm{Hk}_{\text {knee+ankle }}$ & $8.6(-12.7-35.2)$ & $-0.28(-0.32--0.23)$ & $30.6(21.5-55.2)$ & $0.25(-0.35-0.69)$ & Poor \\
\hline
\end{tabular}




$\begin{array}{llllll}\mathrm{Hk}_{\text {ankle }} & -0.8(-10.8-10.4) & 0.09(0.07-0.10) & 14.8(10.8-24.7) & 0.76(0.42-0.91) & \text { Moderate* } \\ \mathrm{Hk}_{\text {knee }} & 9.6(-17.5-45.7) & -0.33(-0.37--0.29) & 44.5(31.3-79.8) & 0.14(-0.38-0.60) & \text { Poor } \\ \mathrm{Hk}_{\text {hip }} & -6.6(-22.6-12.7) & 0.11(0.06-0.17) & 25.8(18.2-45.9) & 0.81(0.49-0.93) & \text { Poor* }\end{array}$

$3 *=$ at least one reliability parameter was unclear (confidence interval spanned more than one criteria). 


\section{Table 4(on next page)}

Comparison between stiffness measures for running at $5.0 \mathrm{~min} / \mathrm{km}$ and hopping at 2.2 $\mathrm{Hz}$ in triathletes

*- indicates confidence interval spans more than one interpretation bracket 
1 Comparison between stiffness measures for running at $5.0 \mathrm{~min} / \mathrm{km}$ and hopping at $2.2 \mathrm{~Hz}$

\begin{tabular}{|c|c|c|c|}
\hline Method & $\begin{array}{l}\text { Comparison } \\
\text { with }\end{array}$ & $\begin{array}{l}\text { Pearson's Correlation } \\
(90 \% \text { CL) }\end{array}$ & Interpretation \\
\hline \multicolumn{4}{|c|}{ Hopping - Leg } \\
\hline \multicolumn{4}{|l|}{ - Bent Knee } \\
\hline $\mathrm{Hk}_{\operatorname{leg} / \text { dynamic }}$ & $\mathrm{Rk}_{\text {leg/dynamic }}$ & $0.66(0.20-0.88)$ & Moderate* \\
\hline $\mathrm{Hk}_{\text {leg/time }}$ & $\mathrm{Rk}_{\text {leg/time }}$ & $0.53(0.01-0.82)$ & Moderate* \\
\hline $\mathrm{Hk}_{\text {leg/brakeHJC }}$ & $\mathrm{Rk}_{\text {leg/brakeHJC }}$ & $0.55(0.07-0.82)$ & Moderate* \\
\hline $\mathrm{Hk}_{\text {leg/brakeGTR }}$ & $\mathrm{Rk}_{\text {leg/brakeGTR }}$ & $0.34(-0.20-0.72)$ & Poor* \\
\hline \multicolumn{4}{|c|}{ - Straight Knee } \\
\hline $\mathrm{Hk}_{\text {leg/dynamic }}$ & $\mathrm{Rk}_{\text {leg/dynamic }}$ & $0.37(-0.19-0.75)$ & Poor* \\
\hline $\mathrm{Hk}_{\text {leg/time }}$ & $\mathrm{Rk}_{\text {leg/time }}$ & $0.36(-0.20-0.74)$ & Poor* \\
\hline $\mathrm{Hk}_{\text {leg/brakeHJC }}$ & $\mathrm{Rk}_{\text {leg/brakeHJC }}$ & $0.01(-0.49-0.51)$ & Poor* \\
\hline $\mathrm{Hk}_{\text {leg/brakeGTR }}$ & $\mathrm{Rk}_{\text {leg/brakeGTR }}$ & $0.02(-0.48-0.52)$ & Poor* \\
\hline \multicolumn{4}{|c|}{ Hopping - Joint } \\
\hline \multicolumn{4}{|c|}{ - Bent Knee } \\
\hline $\mathrm{Hk}_{\text {sumjoints }}$ & $\mathrm{Rk}_{\text {sumjoints }}$ & $-0.17(-0.62-0.36)$ & Poor* \\
\hline $\mathrm{Hk}_{\text {hip+knee }}$ & $\mathrm{Rk}_{\text {hip}+ \text { knee }}$ & $-0.31(-0.70-0.22)$ & Poor* \\
\hline $\mathrm{Hk}_{\text {knee+ankle }}$ & $\mathrm{Rk}_{\text {knee+ankle }}$ & $0.49(-0.01-0.80)$ & Poor* \\
\hline $\mathrm{Hk}_{\text {ankle }}$ & $\mathrm{Rk}_{\text {ankle }}$ & $0.65(0.23-0.87)$ & Moderate* \\
\hline $\mathrm{Hk}_{\mathrm{knee}}$ & $\mathrm{Rk}_{\text {knee }}$ & $0.49(-0.01-0.79)$ & Poor* \\
\hline $\mathrm{Hk}_{\text {hip }}$ & $\mathrm{Rk}_{\text {hip }}$ & $-0.38(-0.74-0.15)$ & Poor* \\
\hline $\mathrm{Hk}_{\mathrm{knee}+\text { ankle }}$ & $\mathrm{Hk}_{\mathrm{leg} / \mathrm{time}}$ & $0.46(-0.12-0.81)$ & Poor* \\
\hline \multicolumn{4}{|c|}{ - Straight Knee } \\
\hline $\mathrm{Hk}_{\text {sumjoints }}$ & $\mathrm{Rk}_{\text {sumjoints }}$ & $0.63(0.19-0.86)$ & Moderate* \\
\hline $\mathrm{Hk}_{\text {hip+knee }}$ & $\mathrm{Rk}_{\mathrm{hip}+\mathrm{knee}}$ & $0.61(0.16-0.85)$ & Moderate* \\
\hline $\mathrm{Hk}_{\mathrm{knee}+\text { ankle }}$ & $\mathrm{Rk}_{\text {knee+ankle }}$ & $0.73(0.35-0.90)$ & Large* \\
\hline $\mathrm{Hk}_{\text {ankle }}$ & $\mathrm{Rk}_{\text {ankle }}$ & $0.54(0.05-0.82)$ & Moderate* \\
\hline $\mathrm{Hk}_{\mathrm{knee}}$ & $\mathrm{Rk}_{\text {knee }}$ & $0.62(0.18-0.86)$ & Moderate* \\
\hline $\mathrm{Hk}_{\text {hip }}$ & $\mathrm{Rk}_{\text {hip }}$ & $0.47(-0.03-0.79)$ & Poor* \\
\hline $\mathrm{Hk}_{\mathrm{knee}+\text { ankle }}$ & $\mathrm{Hk}_{\mathrm{leg} / \mathrm{time}}$ & $0.57(0.06-0.84)$ & Moderate* \\
\hline
\end{tabular}

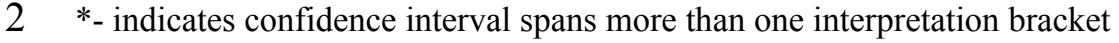




\section{Table 5 (on next page)}

Comparison of vertical and joint stiffness measures with leg stiffness for treadmill running at $5.0 \mathrm{~min} / \mathrm{km}$

$\mathrm{BH}=$ bent knee hopping; $\mathrm{SH}=$ straight knee hopping; *- indicates confidence interval spans more than one interpretation bracket 
1 Comparison of vertical and joint stiffness measures with leg stiffness for treadmill running at 5.0

$2 \mathrm{~min} / \mathrm{km}$

\begin{tabular}{|c|c|c|c|}
\hline Method & Comparison with & Pearson's Correlation $(90 \% \mathrm{CL})$ & Interpretation \\
\hline \multicolumn{4}{|l|}{ Vertical } \\
\hline \multirow[t]{4}{*}{$\mathrm{k}_{\mathrm{vert} / \text { dynamic }}$} & $\mathrm{k}_{\text {leg/dynamic }}$ & $0.89(0.70-0.97)$ & Large* \\
\hline & $\mathrm{k}_{\operatorname{leg} / \mathrm{time}}$ & $0.79(0.45-0.93)$ & Large* \\
\hline & $\mathrm{k}_{\text {leg/brakeHJC }}$ & $0.88(0.68-0.96)$ & Large* \\
\hline & $\mathrm{k}_{\mathrm{ver} / \mathrm{time}}$ & $0.83(0.57-0.94)$ & Large* \\
\hline \multirow[t]{3}{*}{$\mathrm{k}_{\mathrm{vert} / \text { time }}$} & $\mathrm{k}_{\operatorname{leg} / \text { dynamic }}$ & $0.87(0.64-0.96)$ & Large* \\
\hline & $\mathrm{k}_{\mathrm{leg} / \mathrm{time}}$ & $0.91(0.73-0.97)$ & Very Large* \\
\hline & $\mathrm{k}_{\text {leg/brakeHJC }}$ & $0.87(0.65-0.95)$ & Large* \\
\hline \multicolumn{4}{|l|}{ Leg } \\
\hline \multirow[t]{3}{*}{$\mathrm{k}_{\text {leg/brakeGTR }}$} & $\mathrm{k}_{\mathrm{leg} / \mathrm{dynamic}}$ & $0.68(0.25-0.89)$ & Moderate* \\
\hline & $\mathrm{k}_{\operatorname{leg} / \text { time }}$ & $0.64(0.18-0.87)$ & Moderate* \\
\hline & $\mathrm{k}_{\text {leg/brakeHJC }}$ & $0.97(0.91-0.99)$ & Very Large \\
\hline \multirow[t]{2}{*}{$\mathrm{k}_{\mathrm{leg} / \text { brakeHJC }}$} & $\mathrm{k}_{\mathrm{leg} / \mathrm{dynamic}}$ & $0.72(0.32-0.90)$ & Large* \\
\hline & $\mathrm{k}_{\mathrm{leg} / \mathrm{time}}$ & $0.69(0.27-0.89)$ & Moderate* \\
\hline $\mathrm{k}_{\text {leg/time }}$ & $\mathrm{k}_{\text {leg/dynamic }}$ & $0.94(0.83-0.98)$ & Very Large* \\
\hline \multicolumn{4}{|l|}{ Joint } \\
\hline \multirow[t]{4}{*}{$\mathrm{k}_{\text {sumjoints }}$} & $\mathrm{k}_{\operatorname{leg} / \text { brakeHJC }}$ & $0.55(0.06-0.82)$ & Moderate* \\
\hline & $\mathrm{k}_{\text {leg/brakeGTR }}$ & $0.39(-0.13-0.75)$ & Poor* \\
\hline & $\mathrm{k}_{\mathrm{leg} / \mathrm{dynamic}}$ & $0.49(-0.05-0.81)$ & Poor* \\
\hline & $\mathrm{k}_{\mathrm{leg} / \mathrm{time}}$ & $0.61(0.13-0.86)$ & Moderate* \\
\hline \multirow[t]{3}{*}{$\mathrm{k}_{\text {knee+ankle }}$} & $\mathrm{k}_{\mathrm{leg} / \text { dynamic }}$ & $0.75(0.37-0.91)$ & Large* \\
\hline & $\mathrm{k}_{\operatorname{leg} / \operatorname{time}}$ & $0.82(0.52-0.94)$ & Large* \\
\hline & $\mathrm{k}_{\text {leg/brakeHJC }}$ & $0.69(0.29-0.88)$ & Moderate* \\
\hline \multirow[t]{3}{*}{$\mathrm{k}_{\mathrm{hip}+\mathrm{kne}}$} & $\mathrm{k}_{\operatorname{leg} / \text { dynamic }}$ & $0.53(0.00-0.82)$ & Moderate* \\
\hline & $\mathrm{k}_{\mathrm{leg} / \mathrm{time}}$ & $0.66(0.21-0.88)$ & Moderate* \\
\hline & $\mathrm{k}_{\text {leg/brakeHJC }}$ & $0.54(0.06-0.82)$ & Moderate* \\
\hline \multirow[t]{3}{*}{$\mathrm{k}_{\text {ankle }}$} & $\mathrm{k}_{\mathrm{leg} / \mathrm{dynamic}}$ & $0.20(-0.36-0.65)$ & Poor* \\
\hline & $\mathrm{k}_{\mathrm{leg} / \mathrm{time}}$ & $0.28(-0.29-0.70)$ & Poor* \\
\hline & $\mathrm{k}_{\text {leg/brakeHJC }}$ & $0.39(-0.14-0.74)$ & Poor* \\
\hline \multirow[t]{3}{*}{$\mathrm{k}_{\mathrm{knee}}$} & $\mathrm{k}_{\mathrm{leg} / \mathrm{dynamic}}$ & $0.76(0.40-0.92)$ & Large* \\
\hline & $\mathrm{k}_{\operatorname{leg} / \mathrm{ime}}$ & $0.79(0.46-0.93)$ & Large* \\
\hline & $\mathrm{k}_{\text {leg/brakeHJC }}$ & $0.55(0.08-0.83)$ & Moderate* \\
\hline \multirow[t]{3}{*}{$\mathrm{k}_{\text {hip }}$} & $\mathrm{k}_{\operatorname{leg} / \mathrm{dynamic}}$ & $0.17(-0.39-0.64)$ & Poor* \\
\hline & $\mathrm{k}_{\operatorname{leg} / \mathrm{time}}$ & $0.31(-0.25-0.72)$ & Poor* \\
\hline & $\mathrm{k}_{\text {leg/brakeHJC }}$ & $0.32(-0.22-0.70)$ & Poor* \\
\hline $\mathrm{BHk}_{\text {knee+ankle }}$ & $\mathrm{BHk}_{\text {leg/time }}$ & $0.46(-0.12-0.81)$ & Poor* \\
\hline SHk $_{\text {knee+ankle }}$ & $\mathrm{SHk}_{\operatorname{leg} / \mathrm{time}}$ & $0.57(0.06-0.84)$ & Moderate* \\
\hline
\end{tabular}


$3 \mathrm{BH}=$ bent knee hopping; $\mathrm{SH}=$ straight knee hopping; *- indicates confidence interval spans more than one 4 interpretation bracke 